Viso - Cadernos de estética aplicada Revista eletrônica de estética

ISSN 1981-4062

№ 3, set-dez/2007

http://www.revistaviso.com.br/

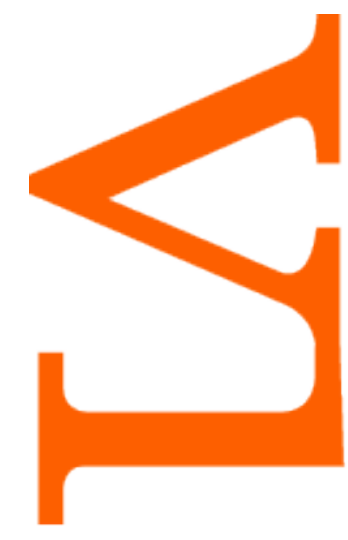

http.//www.revistaviso.com.br/

\title{
Arte e sofrimento: Proust schopenhaueriano
} Liliane Marinho

Universidade Federal do Rio de Janeiro (UFRJ) 


\section{RESUMO}

\section{Arte e sofrimento: Proust schopenhaueriano}

Pretendo analisar neste texto como Schopenhauer e Proust tecem a relação entre Arte e Sofrimento, explicitando que tipo de relação é estabelecida e o estatuto que tais relações recebem em suas obras. Apresentarei brevemente a interpretação schopenhaueriana da existência em $\mathrm{O}$ mundo como vontade e representação, ressaltando o papel da arte em sua concepção do mundo. Tentarei mostrar também como Proust, uma espécie de artista-filósofo, pretende, na obra Em busca do tempo perdido, alcançar a essência da arte e com isso superar o sofrimento inerente à existência. Procurarei, neste sentido, remetendo-me ao filósofo, apresentar a concepção proustiana de apropriação da vida pela arte em busca de seu sentido mais intimo, conduzindo a um modo privilegiado de conhecer e superar o sofrimento.

Palavras-chave: Schopenhauer - Proust - arte - metafísica

\section{ABSTRACT}

\section{Art and suffering: a Schopenhaurian Proust}

This text aims at analysing the relation between art and suffering as depicted by Schopenhauer and Proust. It briefly presents Schopenhauer's concept of existence, highlighting the role of art as it appears in The World as Will and Representation. It also presents how Proust, in his masterpiece In Search of Lost Time, tries to set forth a theory in which art is capable not only of reaching the essence of life, but also of overcoming the suffering experienced as time goes by.

Keywords: Schopenhauer - Proust - art - metaphysics 


\section{MARINHO, L. "Arte e sofrimento: Proust schopenhaueriano". In: Viso: Cadernos de estética aplicada, v. I, n. 3 (set-dez/2007), pp. 47-55.}

\subsection{9/1981-4062/v3i/46}

Aprovado: 27.10.2007. Publicado: 27.12.2007.

(C) 2007 Liliane Marinho. Esse documento é distribuído nos termos da licença Creative Commons Atribuição-NãoComercial 4.0 Internacional (CC-BY-NC), que permite, exceto para fins comerciais, copiar e redistribuir o material em qualquer formato ou meio, bem como remixá-lo, transformá-lo ou criar a partir dele, desde que seja dado o devido crédito e indicada a licença sob a qual ele foi originalmente publicado.

Licença: http://creativecommons.org/licenses/by-nc/4.0/deed.pt_BR

Accepted: 27.10.2007. Publicado: 27.12.2007.

(C) 2007 Liliane Marinho. This document is distributed under the terms of a Creative Commons Attribution-NonCommercial 4.0 International license (CC-BY-NC) which allows, except for commercial purposes, to copy and redistribute the material in any medium or format and to remix, transform, and build upon the material, provided the original work is properly cited and states its license.

License: http://creativecommons.org/licenses/by-nc/4.0/ 
Não seria nenhuma novidade dizer que a grande aspiração de Proust era descobrir um tema filosófico para compor Em busca do tempo perdido. ${ }^{1}$ Jean-Yves Tadié, por exemplo, nos diz que "ao fazer de seu herói um artista, e do tema de sua obra a história de uma vocação, Proust faz da descoberta de sua estética e de sua filosofia o principal acontecimento de seu romance [...]". ${ }^{2}$ O centro das preocupações do autor, no decorrer de toda a obra, gira exatamente em torno dos limites do pensamento, do destino do homem e do estatuto que a arte tem em sua relação com o mundo.

Assim como Schopenhauer não toma as artes simplesmente como objeto de reflexão, mas como parte fundamental de seu sistema de pensamento, Proust estabelece uma ponte entre a abstração dos tratados filosóficos e a realidade que cria para seus personagens. ${ }^{3} \mathrm{E}$, se é possível afirmar que o sistema schopenhaueriano preconiza a arte como uma forma de compreensão mais profunda do mundo, tal como defendido por Anne Henry em seu texto "Proust du coté de Schopenhauer", podemos concordar que "Proust é o escritor que deu ao Mundo como Vontade e Representação a tradução mais literária". ${ }^{5}$

Em vez de se dedicar às especulações teóricas, tal como fez Schopenhauer, Proust preferiu no entanto examinar a vida concreta. E, assim, pôde aderir com tranqüilidade ao sistema do filósofo, tanto pela valorização que nele a arte recebe, quanto pela possibilidade de chegar a uma compreensão privilegiada do sofrimento inerente à existência. Tal como Thomas Mann, Beckett e Conrad, o autor fala da separação dos seres, da ferocidade do ritual social, da descontinuidade dos sentimentos, da angústia da identidade, da incapacidade da linguagem, num registro todavia completamente diferente da atmosfera fúnebre que encontramos nos Buddenbrook, ou nas brincadeiras dos clowns beckettianos.

Proust jamais fez referências explícitas a Schopenhauer, ainda que tenha, muitas vezes, parafraseado suas análises. Entretanto, no momento em que o filósofo se popularizava sobretudo na França, a partir da valorização de sua verve pessimista, e muito em função da música de Wagner - o autor extraiu com maestria a questão fundamental para a compreensão de seu pensamento: como é possível, pela suspensão da esfera egoísta presente nos interesses particulares, alcançar a essência do mundo? Esta é a unidade de pensamento que atravessa silenciosamente todos os sete livros que compõem, nas palavras do autor, "uma longa obra chamada romance, na qual não há contingências, senão nas representações do que é contingente na vida". ${ }^{6}$

Sabemos que, para Schopenhauer, a superação do sofrimento só é possível por um tipo de postura adotada a partir da revelação da essência metafísica do mundo. Para Proust, por seu turno, é a arte que liberta a vida do sofrimento. Podemos dizer que a inevitável aproximação dos dois autores se dá já a partir da estrutura de suas obras, pois ambas são traçadas com a finalidade de revelar uma essência para o mundo, uma vez que consideram sua aparência como sendo marcada pelo espetáculo vazio da incessante substituição de indivíduos fadados a lutar pela sobrevivência. Fundamentalmente 
metafísicas, as duas obras são, a meu ver, determinadas pela relação que estabelecem entre o conhecimento e a aprendizagem.

Schopenhauer dirá que há "três formas de vida humana correspondentes aos três elementos de que, na prática, toda vida é composta". Em primeiro lugar, temos a vontade enérgica, a vida com grandes paixões, que compõe o mundo como aparência - a vontade objetivada no tempo e no espaço, a partir do princípio de individuação. Em segundo, temos as idéias eternas, essencialidades imperecíveis que guardam as qualidades de todos os seres. Finalmente, temos, numa dimensão extra-temporal, a essência das essencialidades, sujeito de todo objeto: a vontade livre que, em si mesma, não passa de impulso cego, fadada à eterna contradição e ao divórcio, pois é, ao mesmo tempo, o que amalgama todos os seres e o que inevitavelmente os leva à condição de indivíduos. Sempre onde há vida, há vontade, há disputa, há divórcio, há contradição. Presos ao primeiro nível,

a vida de cada um de nós, se a abarcarmos em seu conjunto com um só olhar, é uma verdadeira tragédia: os desejos nunca atendidos, a dor sempre gasta em vão, as esperanças quebradas por um destino impiedoso, os desenganos cruéis que compõem a vida inteira, o sofrimento que vai aumentando, e, na extremidade de tudo, a morte. Completando com escárnio, a fatalidade de nossa existência não nos reserva nem mesmo a dignidade do personagem trágico, e a cada dia de trabalho, a cada novo engano, os desejos satisfeitos apenas para serem substituídos incessantemente por novos desejos, reduz a vida a uma verdadeira comédia, reservando-nos o papel de bobos. ${ }^{7}$

Do ponto de vista da representação, o mundo é dado a partir de uma unidade indivisível entre sujeito e objeto na qual o primeiro é aquilo que conhece todo o resto, sem ser ele mesmo conhecido: "O sujeito é o substratum do mundo, a condição invariável, sempre subentendida de todo fenômeno, de todo objeto". ${ }^{8}$ Todos os objetos que se apresentam na representação total, construindo o conjunto da realidade empírica estão, no que diz respeito ao curso do tempo, ligados uns aos outros. ${ }^{9}$ Preso ao nível da representação, o homem sempre será o lobo do homem, pois sempre estará sempre preso à existência limitada pelo tempo e pelo espaço, seguindo os ditames de uma imperadora faminta que amalgama todo os seres, sem conseguir libertar-se do ciclo vicioso entre o desejo e o tédio.

Devemos distinguir, no entanto, a representação submetida ao principium indivituationis (sujeito/objeto) e ao princípio de razão suficiente do poder de conhecimento superior que supera os conceitos da razão e nos dá acesso às essências da essencialidade, a um significado mais profundo do mundo como representação. É o conhecimento que obtemos através da contemplação estética. Christopher Janaway considera a estética uma figura central da filosofia de Schopenhauer. De acordo com o autor, "a arte e a experiência estética não apenas funcionam como uma libertação da existência, considerada numa outra forma como miserável, mas atingem uma objetividade explicitamente superior à da ciência ou à do conhecimento comum". ${ }^{10}$ 
Para complementar sua concepção do mundo, Schopenhauer retoma de Platão o conceito de idéia. Segundo a utilização que faz do modelo kantiano, a coisa-em-si é a vontade e a idéia é sua objetidade ${ }^{11}$ imediata. Pode-se dizer, então, que a idéia é a ponte entre a coisa-em-si, inacessível e irrepresentável, e o fenômeno. Diferentemente do conhecimento que temos do fenômeno, submetido ao princípio de razão, as idéias eternas, por se encontrarem fora do tempo e da pluralidade dos seres, podem oferecer um conhecimento seguro do mundo.

Para termos acesso às idéias, segundo Schopenhauer, o mundo tem de se resumir a um nunc stans, possibilidade oferecida pela contemplação estética que pára a roda do tempo e arranca o indivíduo do mundo fenomenal, transformando-o em sujeito puro do conhecimento e transformando o objeto contemplado em idéia. Uma maçã pintada por Cézanne, por exemplo, não representa nenhuma maçã individualmente, e sim a essência da maçã, pois se encontra completamente livre de qualquer relação funcional operada no mundo dos fenômenos. Este conhecimento, no entanto, não conduz à completa resignação da vontade, funcionando apenas como um calmante momentâneo. Somente através de um ascetismo excepcional somos capazes de alcançar o nível mais elevado de conhecimento da vontade e, em conseqüência disso, cessá-la totalmente. Assim, do ponto de vista do conhecimento, ainda que a contemplação artística revele a essência do mundo, segundo o que pensa o filósofo, ela o faz limitadamente. E é neste momento que se pode estabelecer um rompimento entre Proust e Schopenhauer.

Num comentário ao primeiro volume ${ }^{12}$ de Em busca do tempo perdido, Thierry Lagêt o descreve como um verdadeiro laboratório das experiências humanas. Estudiosos e leitores devem assumir o papel de caçadores da ave do paraíso que, a cada página, alça vôo, transformando-se em pássaros multicoloridos. Seguir o vôo desses pássaros significa perscrutar o mistério das grandes obras, tarefa ao mesmo tempo solitária e confortante. Solitária por descobrirmos através dela os limites das experiências circunscritas na inexorável condição humana; confortante por ecoar em cada frase a voz de todos seus leitores, e, por que não dizer, a voz da própria humanidade.

Proust impôs-se a tarefa de desvendar o mistério da existência, de descobrir uma saída para o sofrimento, uma justificativa para a queda do paraíso, algo que pudesse conciliar dor e prazer. A saída encontrada pelo autor é a arte. Se, como propõe Anne Henry no texto "La révelation d'une philosophie de l'art"13, pode-se dizer que Proust extrapola o nível da literatura para constituir uma filosofia da arte, radicalizando o elogio que Schopenhauer faz à arte na $3^{a}$ parte de $O$ mundo como vontade e representação, é porque o autor a transforma no ápice do movimento dialético da Recherche.

Em seu Proust ${ }^{14}$, Beckett assinala que o literato apresenta na Recherche uma concepção da vida como uma sucessão de hábitos, da mesma forma que o indivíduo é uma sucessão de indivíduos. Retomando Schopenhauer, nossa existência oscila como um pêndulo entre o sofrimento e o tédio, verdade que é revelada pelos períodos de transição entre o aparecimento e a satisfação de um desejo nos quais o tédio de viver é 
substituído pelo sofrimento de ser. A verdadeira sabedoria reside, portanto, não na satisfação dos desejos mundanos, mas em sua extirpação, o que torna o rompimento do hábito condição fundamental para a criação estética. Podemos estabelecer uma analogia entre o rompimento do hábito e a contemplação estética, pois o hábito esconde a essência do objeto; ele é, como afirma Proust, "uma segunda essência que nos conserva em ignorância da primeira e está livre de suas crueldades e encantos". ${ }^{15}$ Neste sentido, é o hábito que impede a percepção da verdadeira realidade das coisas.

Para compreendermos como essa realidade é revelada, muito nos auxilia a interpretação de Deleuze, para quem, "aprender diz respeito essencialmente aos signos". ${ }^{16}$ Sejam eles os signos da mundanidade, do amor, das impressões sensíveis ou signos artísticos, é através deles que podemos identificar unidades de sistemas na pluralidade de mundos que a obra de Proust apresenta. Assim, o processo de aprendizado é um processo de decifração de signos. E como há sempre uma espécie de vocação para os signos, é interessante notar a evolução da obra em direção ao signo artístico. Isto demonstra, por exemplo, por que Swann, um de seus personagens mais importantes, não vai além de sua experiência pessoal quando ouve a pequena frase da sonata de Vinteuil, fixando-se no que Schopenhauer descreve como uma apreciação equivocada da música, na qual tendemos a associá-la a objetos ou imagens. No caso de Swann, ele dá um sentido biográfico à pequena frase de Vinteuil, identificando nela seus sentimentos por Odette.

Cabe somente àquele que é dotado de uma capacidade extraordinária de se fixar na contemplação desinteressada da essência do mundo, o que caracteriza o gênio, penetrar na sua essência e imortalizar o tempo em estado puro. Somente a arte é capaz de superar tanto os movimentos da subjetividade quanto as propriedades do objeto, alcançando a essência. É apenas no nível da arte que as essências são reveladas. Mas, uma vez manifestadas na obra de arte, elas reagem sobre todas as esferas da realidade. Nas palavras de Proust, em O tempo redescoberto, "para escrever o livro essencial, o único verdadeiro, um grande escritor não precisa, no sentido corrente da palavra, inventá-lo, pois ele já existe em cada um de nós. Precisa sim de traduzi-lo". ${ }^{17}$

Proust vê na arte a possibilidade de expressar a alegria e a tristeza de uma forma que ultrapassa a vida ordinária e dá acesso à eternidade, o que possibilita a redescoberta do tempo, e conseqüentemente a superação do sofrimento. $O$ mais curioso é que a revelação da essência do tempo só acontece no último volume da obra; o percurso do narrador, como bem assinalado por Deleuze, não diz respeito à memória ou à lembrança, ele é a busca pela verdade do tempo perdido. Tempo perdido que "não é simplesmente o tempo passado; é também o tempo que se perde, como na expressão 'perder tempo'". ${ }^{18}$ Assim, nos dirá Proust,

cada criatura que nos faz sofrer pode representar para nós uma divindade da qual é apenas um reflexo fragmentado, uma derradeira manifestação. Esta divindade, contemplada do ponto de vista da idéia, ou seja, a partir da eternidade logo transforma em alegria a dor que experimentávamos. A arte de viver consiste em sabermos nos servir de quem nos atormenta como de degraus de acesso à sua forma divina, 
povoando assim, diariamente, nossa vida de deuses. Satisfazia-me verificar essas verdades. Então, menos brilhante, sem dúvida, do que a que me fizera vislumbrar na obra de arte o único meio de reaver o Tempo Perdido, nova luz fez-se em mim. E compreendi que a matéria da obra de arte era, afinal, minha vida passada; que tudo me viera nos divertimentos frívolos, na indolência, na ternura, na dor... ${ }^{19}$

É deste modo, portanto, que o grande paradoxo do tempo, senhor da danação e da salvação, é desvendado. Proust mostra que é exatamente sua passagem que vai permitir sua permanência.

Para concluir, penso que, extrapolando a genialidade literária, a importância de nos debruçarmos sobre a Recherche com olhos filosóficos está em reconhecer os elementos que remetem ao par arte-filosofia apropriados pelo autor para desenvolver suas próprias teses e criar, segundo determinados princípios, não só uma concepção da música, da pintura ou da literatura, mas uma teoria da arte. A meu ver, Proust foi determinante para o estabelecimento da arte como uma atividade autônoma capaz de justificar a existência e expandir os limites do humano.

\section{* Liliane Marinho é doutoranda em filosofia pela UFRJ/PPGF.}

1 Obra desenvolvida em sete volumes a qual farei referência no decorrer deste texto como Recherche.

2 TADIÉ, J.-Y. Le roman au XXè. siècle. Paris: Belfond, 1990, p. 180. Jean-Yves Tadié foi o responsável pela edição atualizada da Recherche em 1987, publicada originalmente em 1954 pela Pléiade, Éditions Gallimard.

${ }^{3}$ HENRY, A. Marcel Proust: Théories por une esthétique. Paris: Klincksieck, 1983, 2a. ed., pp. 710.

${ }^{4}$ In: HENRY, A. (org.) Schopenhauer et la création litteraire en Europe. Paris: Klincksieck, 1989.

${ }^{5}$ Ibidem, p. 149.

${ }^{6}$ PROUST, M. Correspondance. Edição em 20 volumes organizada por Philip Kolb. Paris: Plon, 1972-1990, t. XI, p. 287.

${ }^{7}$ SCHOPENHAUER, A. O mundo como vontade e representação. Trad. M.F. Sá Correia. Lisboa: Contraponto, 2001, p. 338.

8 Ibidem, p. 11.

${ }^{9}$ Este tema é desenvolvido por Schopenhauer em sua tese de doutorado, intitulada "Sobre a quádrupla raiz do princípio de razão suficiente".

10 JANAWAY, C. "Knowledge and tranquility" (39) In: Schopenhauer, philosophy, and the arts. Cambridge: Cambridge University Press, 1996, pp. 39-60.

${ }^{11}$ Observamos uma variação no uso dos termos objetidade, objetividade adequada e objetivação, referindo-se respectivamente à idéia, à união do sujeito puro de conhecimento com a idéia e ao fenômeno.

12 PROUST, M. Du côté de chez Swann. Paris: Gallimard, 1992. 
${ }^{13}$ HENRY, A. (org.) Marcel Proust: Théories pour une esthétique. Paris: Klincksieck, 1983, pp. 4497.

${ }^{14}$ BECKETT, S. Proust. Tradução de Arthur Nestrovski. São Paulo: Cosac \& Naify, 2003, p. 17.

${ }^{15}$ Cf. Ibidem, p. 21.

16 DELEuZE, G. Proust e os signos. Tradução de Antonio Piquet e Roberto Machado Rio de Janeiro: Forense, 1987, p. 4.

17 PROUST, M. Em busca do tempo perdido, vol. 7. Tradução de Lúcia Miguel Pereira. Rio de Janeiro: Editora Globo, 1983, p. 138.

${ }^{18}$ DELEUZE, G. Op. cit., p. 3.

${ }^{19}$ PROUST, M. Em busca do tempo perdido, vol. 7. Op. cit., pp. 144-5. 